\section{MATÉS BARCO, Juan Manuel y ROJAS-RAMÍREZ, José Juan Pablo (eds.). 2018: Agua y servicios públicos en España y México, Jaén, UJA Editorial \& Universidad de Guadalajara (México), 293 págs. ISBN: 978-84-9159-125-2. EAN: 9788491591252.}

Desde la estructuración del Estado moderno, el manejo del agua ha representado un tema de gran envergadura. En la actualidad, ante una crisis hídrica derivada del uso excesivo y de la gestión ineficiente, el debate que se presenta en esta obra resulta en un dilema necesario de ser abordado: cómo construir una gestión democrática, equitativa y sustentable no sólo para nuestra generación, sino para el futuro de la vida en el planeta.

El conjunto de trabajos que nos presenta el libro Agua y Servicios Públicos en España y México, coordinados por Juan Manuel Matés-Barco de la Universidad de Jaén, España y José Juan Pablo Rojas-Ramírez de la Universidad de Guadalajara, México y publicado por la Editorial Universidad de Jaén en 2018, es una obra que resulta de gran interés para aquellos interesados en el tema de la gestión de los servicios públicos y fundamentalmente del debate acerca de si ésta debe ser pública o privada. Desde una perspectiva histórica, económica y social, se realiza un acercamiento al complejo mundo de los servicios públicos y, especialmente, a la gestión del abastecimiento de agua para consumo humano.

Para estructurar este debate, la presente obra se compone a partir de un conjunto de nueve trabajos que analizan el manejo del agua como parte de un servicio, ya sea prestado por instituciones del Estado o por organismos privados. En el primer texto "De la regulación a la privatización y viceversa: La gestión del agua en España y Reino Unido", Juan Manuel Matés-Barco nos adentra al tema a partir de una exhaustiva revisión bibliográfica sobre la evolución de la gestión del agua en Estados Unidos de América y España, en donde se pone de manifiesto la importancia de la regulación en la gestión del recurso toda vez que ésta tiene características específicas que requieren de una importante supervisión para su correcto funcionamiento.

Siguiendo con la anterior perspectiva, Alberto RuizVillaverde nos presenta "Entendiendo la privatización del agua", en donde a partir de un análisis de estudio de caso, nos va mostrando cómo se fueron dando las decisiones de estatización y reprivatización a partir de analizar las eficiencias y las capacidades financieras. A lo largo del capítulo analiza algunos factores que explican la decisión de los gobiernos que optaron (o no) por la contratación externa.

Por su parte, en el texto "Titularidad del proveedor y eficiencia en el servicio urbano de aguas" de Marta Suárez-Varela Maciá, encontramos una comparación entre la gestión público / privada a partir de distintos análisis de eficiencias realizados en múltiples países. Comparando esta literatura se obtiene que más trabajos abogan por una mejor eficiencia en los servicios públicos toda vez que su visión involucra equidad social, eficiencia económica y sostenibilidad ecológica. Por su parte, indica que los parámetros utilizados para medir eficiencia impiden el análisis de las empresas mixtas que -según la autora-, parecerían como bastante pertinentes a la hora de analizar una buena gestión del recurso.

"El abastecimiento de agua en Málaga (1860-1930): De negocio privado a servicio público" de Víctor Manuel Heredia-Flores analiza el caso de la ciudad de Málaga en España, en donde la industrialización convirtió al agua en un producto de la economía de mercado y desde entonces la evolución hacia un sistema de suministro universal domiciliario de agua potable ha presentado notables cambios desde varios puntos de vista: técnico, económico, político, jurídico y empresarial. Finalmente, da cuenta de la ausencia de controles sanitarios y de adecuados sistemas de saneamiento, que posibilitan que las aguas negras terminen por contaminar los pozos y los manantiales subterráneos.

"Del balneario a la mesa": la industria del agua envasada en España, 1875-2016, escrito por Elvira Lindoso-Tato y Margarita Vilar-Rodríguez, es un repaso histórico de la industria de agua embotellada en España, los cambios de titularidad y la importante presencia de estas empresas al reconvertir el producto en agua embotellada para consumo humano. Con una perspectiva histórica, el texto muestra cómo España ha escalado posiciones en el subsector del agua envasada y se encuen- 
tra, hoy en día, en los primeros puestos de países tanto en producción como en consumo de agua embotellada.

Más adelante, el libro transita hacia la experiencia mexicana, que abre su recuento con el capítulo titulado "La gestión del agua en las ciudades de México: Una retrospectiva en torno a la descentralización" de José Juan Pablo Rojas Ramírez, Alicia Torres Rodríguez y Alejandro Díaz Guzmán. En perspectiva histórica y con análisis documental, se relata el proceso de gestión del agua, desde el porfiriato pasando por la revolución mexicana y la centralización de la gestión, hasta la desconcentración en los ochenta.

Completando la visión anterior, "La ciudad y la falta de agua. Zacatecas en el siglo XIX" de Evelyn Alfaro Rodríguez nos muestra cómo se gestionó la falta de agua en Zacatecas con la iniciativa privada. Empresas que nunca llegaron a concluir los contratos establecidos y por tanto dejaban a la población sin líquido. Según la autora, agua había, pero faltaba un adecuado sistema de distribución y una mejor vigilancia y administración que dejara de lado los intereses particulares de la clase política zacatecana.

De igual forma, "El aguador y el abasto urbano en la ciudad de Zacatecas, México (1887-1910)” de José Raúl Reyes-Ibarra nos muestra la importante función de la participación de los aguadores quienes al igual que en la época colonial, durante el siglo XIX y principios del $\mathrm{XX}$, realizaban la venta ambulante del líquido obtenido de arroyos, fuentes y pozos públicos para distribuirlo por las calles de la ciudad.
Finalmente, "Los efectos del desarrollo urbano e industrial de la ciudad de México sobre el municipio de Naucalpan de Juárez, Estado de México, 1890-1990" de Rebeca López Mora hace un recorrido histórico por este municipio, actualmente conurbado de la Ciudad de México, en donde se registra el deterioro de las fuentes de agua a medida que se da el crecimiento urbano e industrial en esta localidad, a partir de lo que la autora define como los cambios metabólicos.

A partir de la lectura de los artículos contenidos en esta obra, el lector puede adentrarse en la discusión actualizada, y por demás relevante, de la forma de organización que las comunidades humanas han encontrado para la gestión del agua y las dificultades que se han ido evidenciando, a lo largo de la historia, para el logro de una gestión cada vez más democrática, equitativa y sustentable. El reconocimiento de estas dificultades posibilita avanzar hacia la construcción de capacidades para encontrar mejores soluciones al basto problema que aquí se visualiza.

Siendo el agua un tema de vital importancia, y la gestión urbana de la misma una cuestión de la que depende la mayoría de las personas en el planeta, las discusiones sostenidas en este libro adquieren relevancia no sólo para lectores de los países involucrados, sino también para la academia en general.

Karina Kloster Universidad Autónoma de la Ciudad de México karina.kloster@uacm.edu.mx 